\title{
The Use of Information Systems (GIS) to Monitor the Quality of Life of Older People in Greece
}

\author{
Dermatis Zacharias ${ }^{1}$, Anastasiou Athanasios ${ }^{2}$, Liargovas Panagiotis ${ }^{3}$ \\ ${ }^{1} \mathrm{PhD}$, Department of Economic Studies, University of Peloponnese Greece, Greece \\ ${ }^{2}$ Assistant Professor, Department of Economic Studies, University of Peloponnese Greece, Greece \\ ${ }^{3}$ Professor, Department of Economic Studies, University of Peloponnese Greece, Greece \\ Correspondence: Anastasiou Athanasios, Assistant Professor, Department of Economic Studies, University of \\ Peloponnese Greece, Greece.
}

Received: January 8, 2019

Accepted: April 26, $2019 \quad$ Online Published: May 16, 2019

doi:10.5539/ibr.v12n6p29

URL: https://doi.org/10.5539/ibr.v12n6p29

\begin{abstract}
The aim of the study is to present the usefulness of Geographic Information Systems (GIS) to explore the socio-economic indicators that affect the health level of the elderly. The study uses a specially designed questionnaire to capture data on socio-economic indicators of the elderly in Grece. The results of the survey are plotted in the corresponding geographical locations on the maps, using GIS in a way that provides the person concerned a full picture of the geographical distribution of socio-economic indicators that affect the health level of the elderly. The study finds that there is an obvious proportional relationship between Sense of Quality of Life with healthier characteristics, a less proportional relationship with financial characteristics and even a less proportional relationship with the age and the education level of the respondents. The study has implications for health sector professionals and policy makers in Greece.
\end{abstract}

Keywords: GIS, socioeconomic factors, elderly people, quality of life, e-health

\section{Introduction}

The public health sector is a complex and controversial area. In recent years, the work of healthcare professionals has become increasingly effective due to the use of Information and Communication Technology services. There are many problems and challenges in relation to the public health sector. Recently, the use of Geographic Information Systems (GIS) and the spatial representation of various health issues help health professionals to provide better public health services and make better decisions (Fradelos et al., 2014).

GIS are increasingly recognized as an important instrument for the management of health data, for mapping of health indicators, for distribution of disease impacts and analysis and for finding the location of health facilities and services (Garner et al., 1993). Researchers today use modern GIS systems and other mapping applications to address various health problems. Forecasting as well as simulation models rely on these systems (Taylor et al., 2013).

On the other hand, the interest in developing and using life quality assessment tools is wide nowadays. In the 1970s, the first questionnaires on health-related quality of life aimed at measuring the health outcomes in a multidimensional way, including physical, mental and social health measurements. In medical literature, since 1970, it has been observed that a steadily growing number of researchers include the concept of quality of life in relation to the health of the individuals. Today, most studies on clinical intervention results include some form of measurement of health-related quality of life (Yfantopoulos, 2007).

Classical indicators can capture the impact and duration of illnesses in society, but they do not attribute the real impact that patients have on their illnesses and complications because they are based on health-care unit data. Classical indicators cannot be used to assess the patient's visual angle, nor can they provide useful data for assessing the social effects of a disease or its treatment.

The purpose of the current study is to investigate the socio-economic indicators that affect the health level of the elderly by using a specially designed questionnaire. The quantitative data method has been selected for the survey, which allows the systematic collection of objective numerical data and then its performance in numerical 
form for purposes of statistical analysis. More specifically, a specially designed questionnaire was used in print and in electronic form. The objectives of this study are: i) To record the current profile of the elderly in the country's Open Centres of Elderly Care, as it is in the period of the economic crisis. ii) To explore the perception of the elderly about the impact of the economic crisis on their health and lifestyle. (iii) To assess the factors that affect the quality of life of elderly. (iv) To investigate the degree of correlation between socio-economic indicators and the quality of life of older involved in that research. v) To explore the differentiation of the degree of correlation between socio-economic indicators and the quality of life of the elderly.

Given the usefulness of GIS and their application in the areas of physical health, mental health, health services and general health management, the results of the survey were mapped as graphs in the respective geographic locations on the maps, providing the person concerned with a full picture of the geographical distribution of economic and social characteristics and, above all, the health status of the elderly by region. Thus, the public institutions and health service providers concerned are given the opportunity to take prompt decisions on their actions.

In order to obtain valid and scientific results, a representative sample of the studied population was collected, i.e. 897 questionnaires, so that the results and conclusions drawn from them and related to the particular population could be generalized. Methods of Descriptive Statistics (calculation of frequencies and frequency distributions, central trend indicators, dispersion) were applied in order to present the study data and to draw conclusions about the population under investigation.

For the present study the quantitative approach is followed by the large population. The quantitative approach allows research to be conducted on a large part of the target population and "allows the researcher to learn what is happening but does not give interpretation to understand the experience". It also follows the principle of generalizing a conclusion from the specimen under study in a minor proportion of the population (Cohen \& Manion, 1994).

The following Section 2 describes the applications of Geographic Information Systems in Health and the correlations between the different socio-economic factors and the quality of health. Section 3 presents the methodology followed for its implementation, and the final Section presents the conclusions of the study.

\section{Literature Review}

\subsection{Applications of Geographical Information Systems in Health}

The use of GIS systems is widely applied to public health and many studies are based on them. Public Health Informatics (PHI) is an emerging specialty, which focuses on the application of information technology and technology to the practice of Public Health and Research (Hanchette, 2003). As part of this effort, a GIS or, more generally, a Spatial Decision Support System (SDSS) offers improved geographic imaging techniques, resulting in faster and better decision making in the field of Public Health (Yasnoff \& Miller, 2003).

GIS techniques are used to show the lack of correlation between causes and effects or between different outcomes. GIS can contribute to Public Health in many ways because they can provide information on many issues and support the decision-making process properly. They can provide information on the distribution of health services. Thus, any disparities that are increasing continuously could be abolished. Also, policy-makers can be helped and made the right decisions. Health professionals can easily identify the difficulties and inequalities in accessibility to health services and thus be able to cope with the current situation (Foley, 2002). For example, eliminating inequalities in health is one of the two primary goals of the Healthy People 2010 program currently in the US. The use of GIS can play an important role in this effort by helping Public Health professionals to identify the areas of weakness and inequality and helping them ideally to identify and develop solutions to address these deficiencies. GIS can also help researchers integrate dissimilar data from a wide range of sources, and can still be used to impose quality control measures on these data.

The use of GIS has increased exponentially to solve various public health issues. These systems are critical to assessing and addressing relevant health problems in different areas of the earth (Foley, 2002).

A GIS can play an important role in the surveillance, management and analysis of diseases. It appears to be an important tool for the analysis and presentation of epidemiological data. Public health services, diseases, as well as any health information can be mapped and associated with various information such as environmental data, health and social data.

This creates a means of monitoring and managing disease and health programs. It is necessary to understand, monitor and emphasize the reasons that may be related to the development of a disease. Some of these factors could be the environment, behaviour and the socio-economic level of a region. If the "source" of the disease is recognizable and its development and transmission is known, health managers will be able to cope effectively 
with pandemics (Najafabadi, 2009; Ezatti et al., 2005). A GIS system is a tool with great potential that could contribute to assessing environmental risks and human exposure to them.

The design of home care is one of the most active applications of GIS. A GIS can help to organize all the routes that a healthcare professional should follow, taking into account many parameters. On the other hand, private health services could organize an extension plan to promote their services. They can even make forecasts for some services that are in great demand in specific areas. In general, the fields of application of GIS could be applied to strategic planning, research and evaluation, emergency preparedness and the availability and location of health care services (Smith et al., 2007). GIS provide enormous convenience for healthcare providers in organizing and managing health services. Therefore, the organization and coordination of the various services is easier and more efficient. The healthcare provider can quickly and efficiently direct the patient to appropriate health care services (Najafabadi, 2009). GIS are able to provide the exact location of special medical devices. It is important that an insurance organization be able to know the closest location for access to a CT scan when requested by the insured person (Smith et al., 2007).

\subsection{Socio-economic Factors}

There are many bibliographical references demonstrating the strong positive correlation between socio-economic status (SES) and health for many populations in many social sectors (Adler \& Ostrove, 1999; Feinstein 1993; Von dem Knesebecketal., 2006; Kitagawa \& Hauser 1973 Marmot, et al., 1997). Moreover, there is ample literature on the causal mechanisms of linking socio-economic dimensions and health. For example, education is considered to promote good health not only through the creation of financial resources (income and employment) but also through the provision of socio-psychological resources, i.e. healthy behaviours (Ross \& Wu, 1995; Mirowsky \& Ross, 1999), anxiety ability (Lantz et al., 2005; Lin \& Ensel, 1989), self-control (Mirowsky \& Ross, 1998; Taylor \& Seeman, 1999) to better manage disease and disease (Goldman \& Smith, 2002).

Income has been shown to promote health by influencing diet, quality of housing, exposure to environmental hazards, stress, and access to adequate health care (Cohen et al., 2003, Hayward et al., 1988; et al., 1994; House, 2002; Lantz et al., 2005). Individuals or families with low income are particularly vulnerable because they may not be able to have good physical and mental health (Andrulis 1998), restriction of access to healthy foods (Darmon et al., 2002; Caraher et al., 1998) , resulting in toxic environments (Evans \& Katrowitz, 2002) and unhealthy housing conditions associated with a high risk of illness (Rosenbaum, 2008). Further research has shown that income is more closely linked to the evolution (rather than onset) of the disease than the level of education (Herd et al., 2007; Zimmer \& House, 2003), suggesting that the financial resources promote health in part by increasing the person's ability to pay for medical care and to transfer it to appropriate health care units.

Many studies highlight the causal mechanisms by which the socio-economic situation affects people's health. According to Figure 1, the causal relationships between health and socio-economic status, in socio-political-economic conditions, to the extent that they facilitate or interfere with the mechanisms through which a person's socio-economic condition affects health (Link \& Phelan, 1995). Link and Phelan (1995) argue that social factors greatly affect health and hence the emergence of diseases with various mechanisms.

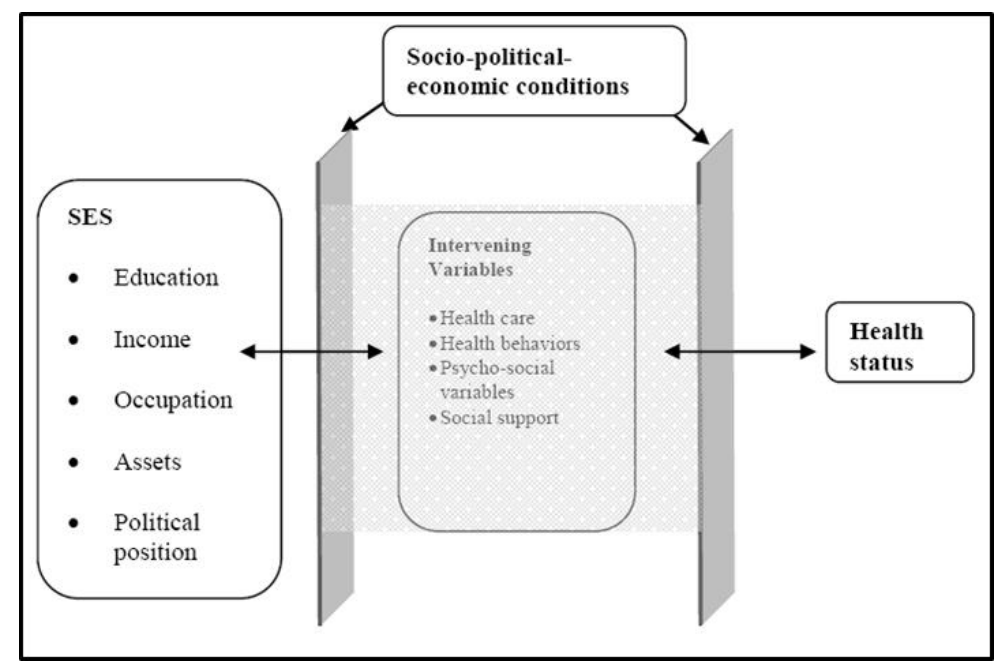

Figure 1. Socio-economic Factors and Health

Source: Link \& Phelan, 1995 


\subsection{Socio-Economic Indicators in Health of the Elderly}

The relationship between socio-economic status and health is an adequately documented epidemiological study. Studies carried out in the United States (Antonovsky, 1967; Kitagawa \& Hauser, 1973; Palmore, 1982; Haan et al., 1987; Kaplan et al., 1987; Feldman et al. et al., 1990; Menchik, 1993;) confirm that socio-economically disadvantaged individuals have higher mortality than those with higher education, increased income, or good working conditions.

Research in the field of social epidemiology and health sociology has repeatedly shown that people belonging to low socio-economic groups face health problems and live less in relation to people in high socio-economic groups (Machenbach et al., 1997). Within the context of these differences, Huisman et al. (2004) conducted an investigation into people aged 65 and over to investigate the relationship between their socio-economic situation and mortality. The survey was based on data from mortality registers of population data from 11 countries and regions in Europe. The indicators of the socio-economic situation studied were the educational level and the permanent residence. The results of the survey showed that absolute and relative socio-economic inequalities in mortality remain at older ages between men and women, and socio-economic disparities in mortality were higher among the elderly and middle-aged people in some populations, although the relative age-based inequality showed differences in population by gender. Also, the correlation between the socio-economic situation and mortality in the $90+$ age group was evident. According to the results of the survey, it is evident that the absolute socio-economic inequalities in mortality increase with age, while the relative socio-economic inequalities in mortality decrease with respect to age. Overall, socio-economic inequalities relative to housing were lower than those of education in the two largest age groups. The authors conclude that such inequalities are a major public health problem in Europe.

The issue of socio-economic inequalities in the field of morbidity and mortality has attracted a large number of researchers, but comparatively few have been centred on the elderly. The study by Huisman et al. (2004) makes a significant contribution to the bibliography on inequalities and mortality, and stresses the importance of examining elderly people in public health policy and actions. This is an issue of increasing importance given the aging of the population in developed countries and the increase in life expectancy and the poor health of people dying over 60 years of age.

The aim of the Grundy \& Holt study (2001) was to identify the most commonly used indicators of socio-economic status (social class, educational level, income, household financial resources, poverty indicators, housing and car ownership). A home interview was conducted at 3,543 participants aged 55-69 in 1988/9 and 2243 were interviewed again in 1994. All indicators were significantly correlated with differences in the elderly's self-reporting of health. The best pair of variables, according to the criteria used, was the educational level or the social class combined with an indicator of poverty.

According to numerous studies, differences in health from the socio-economic situation are smaller for young adults and increase with increasing age (House et al., 1990; 1994, Beckett, 2000). The main explanation for the existence of health inequalities for the elderly is the lowering of the levels of health at a later stage of their life which may be due to psychological factors contributing to poor health (House et al., 1994) such as: (1) lack of social relationships and social support; (2) changes in the elderly's psychological mood such as reduced sense of sovereignty, optimism, sense of control and self-esteem, or increased levels of anger and hostility, and (3) chronic and acute anxiety in life, including the anxiety of marginalization, taxonomy and other phenomena related to the social distribution of power and resources (Lantz et al., 1998).

Another explanation of health inequalities is also due to the natural deterioration of the organism by increasing age (Hayflick, 1998), which plays a key role in identifying the elderly (House et al., 2005; Mirowsky \& Ross 2008). This explanation gives the hypothesis of convergence (Graph 1) that aging of the population serves to reduce health inequalities. A series of studies question the above hypothesis, showing that health inequalities based on the socio-economic situation continue to widen among the elderly, thus giving the case of divergence (Graph 1).

Education is related to the growing disparity in the health status of the elderly (Dupre, 2008; Mirowsky \& Ross, 2008; Willson et al., 2007; Mirowsky \& Ross, 2005).

Long-term economic distress seems to have cumulative effects on the health of older people (McDonough \& Berglund, 2003; Benzeval \& Judge, 2001; Lynch et al., 1997). 


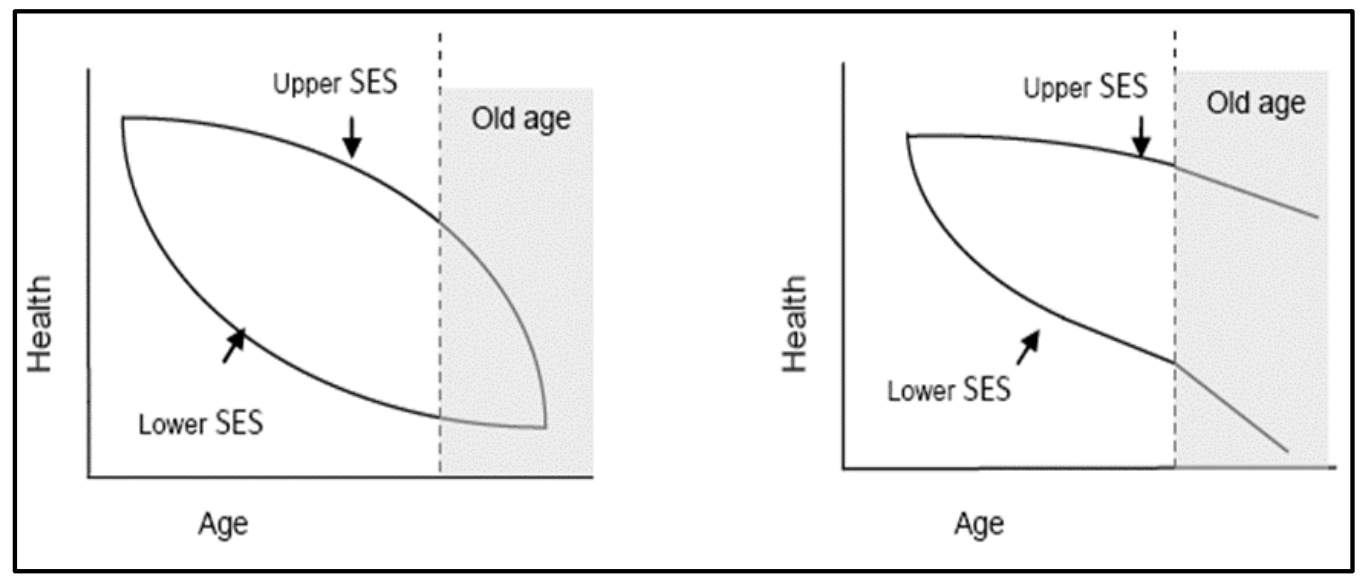

Graph 1. a) Health-age-convergence case and socio-economic situation (left-hand graph, b) Health-age and socio-economic deviation right-hand graph)

Source: Lowry \& Xie (2009)

\section{Research Methodology}

The aim of the survey is to investigate the socio-economic indicators that affect the health level of the elderly. The main objectives of the survey are to record the current elderly profile, explore the perception of the elderly about the impact of the economic crisis on their health status and lifestyle, assess the factors that shape the quality of life of the elderly, the degree of correlation of the socio-economic indicators with the quality of life of the elderly in research and the investigation of the differentiation of the degree of correlation of the socio-economic indicators with the quality of life of the elderly.

Given the usefulness of GIS and their application in the fields of physical health, mental health, health services and general health management, the results of the survey are plotted in the corresponding geographical locations on the maps, providing the person concerned with a complete picture of the geographical distribution of the socio-economic indicators that affect the level of health of the elderly per region. Thus, the public authorities and health service providers are given direct opportunity to take decisions on what they need to do.

For the collection of data, two different approaches, quantitative and qualitative, are presented in the literature. In the quantitative approach, researchers choose to collect primary data, usually from large samples, which then are analyzed properly. Instead, in qualitative research approaches, the logic followed is different, as researchers choose to collect large data from a small sample in order to investigate in depth attitudes and perceptions (Kyriazopoulos \& Samanta, 2010).

For the present study the quantitative approach is followed due to the large population. The quantitative approach allows research to be conducted on a large part of the target population and "allows the researcher to learn" what's going on "but does not give interpretation to understand the experience." It also follows the principle of generalizing a conclusion from the specimen under study in a large proportion of the population (Cohen \& Manion, 1994).

Corresponding surveys have taken place both at European and international level. At European level, a longitudinal survey on health, aging and retirement (SHARE, 2005, Survey on Health, Aging and Retirement in Europe), the first results of which were published in 2005 (Börsch-Supan \& Jurges, 2005). In the survey, initially 11 countries from Scandinavia to the Mediterranean participated, the countries that eventually participated reached 16 (with Israel, Czech Republic, Poland, Ireland, Slovenia). The collection of data is continuously enriched with new data, which are compared with earlier data, thus yielding updated and improved conclusions each time (Börsch-Supan et al., 2008).

In fact, SHARE's development follows faithful studies of the American Health and Retirement Study (HRS) and the English-Longitudinal Study of Aging (ELSA). In addition, many studies on aging have been conducted based on US Health and Retirement Survey (HRS), covering more Asian countries, Russia and African countries (Kapteyn, 2008).

According to Carone and Costello (2006), the importance of such studies lies in the fact that they can make a significant contribution to addressing uncertainty in the demographic and budgetary projections as well as the complex challenges of health care and long-term care policy pensions. Finally, these studies are a valuable tool 
for facilitating difficult political debates on issues related to the quality of life and health of the population and how it is affected by socio-economic factors.

The research tool chosen to carry out this research, was applied to a small sample of elderly people. This small sample collects the characteristics of the final sample of the research, that is, the final set of people to which it is addressed. This pilot survey aims to highlight problems that may arise during the research process. The necessary corrections were made to the questions according to the participants' comments, in order to achieve the following: i) to ensure the reliability and validity of research, ii) to clarity the questions, iii) to estimate the required time to answer the questions, iv) to examine the reaction of the respondents, v) to ensure the completeness of the research tool, vi) to test the usability of the questionnaire, vii) to add more questions if necessary.

For the collection of valid and scientific results, a representative sample of the studied population was collected (Belleli \& Papazoglou, 2004). In order to collect the data and to answer the research questions, questionnaires were distributed to the elderly of different Centers for the Protection of the Elderly (KAPI) in Greece. A total of 897 questionnaires were completed so that the results and conclusions drawn from them and related to this population could be generalized.

The final questionnaire consists of 5 sections and 27 questions.

1. The first section, consisting of 6 questions, relates to the demographic characteristics of the study population (gender, age, marital status).

2. The second section, consisting of 12 questions, refers to the characteristics of the stay of the elderly (area of residence today, area of residence in the past, place of residence, living situation and total number of family members living in the same house).

3. The third section, consisting of 6 questions, relates to the socio-economic characteristics of the elderly (educational level, occupation, main source of income, existence of economic self-sufficiency, annual income).

4. The fourth section, consisting of 8 questions, concerns the medical history of the elderly (health problems, physical energy, health and home restriction, health and activity, smoking, alcohol, diet, sleep, feeling of fatigue after awakening).

5. The fifth section, which consists of 9 questions, is about how the elderly themselves perceive their quality of life. In particular, it refers to the overall quality of life of the elderly, whether they enjoy their lives, whether they are happy most of the time, whether their current economic crisis affects them negatively, whether the pain affects their well-being negatively, and whether health restrict them to the home).

Methods of Descriptive Statistics (calculation of percentages and frequency distributions, central trend indicators, dispersion) were applied in order to present the study data and draw conclusions for the population under investigation.

Parametric methods of analysis were used too In particular, chi-square test and statistical test T-test were used in order to investigate statistically significant correlations. The credibility of the survey is documented by: i) the use of the Cronbach Alpha Trust Factor (0.85), ii) the use of Likert type questions, iii) the use of a pilot survey, iv) the use of clear instructions to answer the questionnaire. Also, the validity of the survey is documented by: i) the use of closed type questions with all possible answers, ii) the anonymity of the survey.

\section{Results}

In order to investigate the association of Life Quality Impacts with certain Demographic Characteristics, Social Characteristics, Economic Characteristics and Health Characteristics, the dependent dummy variable was created called Life Quality Sense, consisting of the Medium Term of Variables Life Quality, Life Enjoyment, and Happiness, mentioned above. The dummy variable was associated with the following independent variables and groups of variables: The first correlation is made with Age variable as Demographic Attribute. The second correlation is made with the Educational Level variable as a Social Attribute. The third correlation is made with the group consisting of the independent variables Economic Autonomy and Annual Income as Economic Characteristics. The fourth correlation is made with the group consisting of the independent variables Physical Energy and Health Sense as Health Characteristics. The results of the linear regression are presented in Table 1, which shows the correlations that have emerged.

From the results, the Life Quality Sense (LQS - values 1 to 5), which was created as a dummy variable from the average of the group of variables Life Quality, Life and Happiness, is related to Age (integer values 1 to 3), as a Demographic Characteristic variable, as follows: 


$$
\text { LQS = 0,191 (Age) + 2,165 }
$$

It also appears that LQS (values 1 to 5 ) is related to the Educational Level (integer values 1 to 9), as a variable of the Social Characteristics, with the following relationship:

$$
\text { LQS = 0,193 (Educational Level })+1,796
$$

Table 1. Association of Life Quality Sense Elements with Demographic, Social, Financial and Health

\begin{tabular}{|c|c|c|c|c|c|}
\hline $\begin{array}{c}\text { Group of Dependent } \\
\text { Variables }\end{array}$ & $\begin{array}{c}\text { Dependent } \\
\text { Dummy Variable }\end{array}$ & $\begin{array}{l}\text { Question } \\
\text { number }\end{array}$ & $\begin{array}{l}\text { Independent } \\
\text { Variables }\end{array}$ & $\begin{array}{c}\text { Linear } \\
\text { Regression } \\
\text { Coefficient }\end{array}$ & $\begin{array}{c}\text { Linear } \\
\text { Regression } \\
\text { Constant }\end{array}$ \\
\hline Life Quality & \multirow{2}{*}{$\begin{array}{c}\text { The Sense of } \\
\text { Quality of Life } \\
\text { LQS }\end{array}$} & \multicolumn{2}{|c|}{ Demographic Characteristics } & A & B \\
\hline $\begin{array}{l}\text { Life Enjoyment } \\
\text { Happiness }\end{array}$ & & 2 & Age & $\begin{array}{c}\mathbf{0 , 1 9 1} \\
(\mathbf{p}=\mathbf{0 , 0 0 0})\end{array}$ & $\begin{array}{c}2,165 \\
(p=0,000)\end{array}$ \\
\hline Life Quality & \multirow{2}{*}{$\begin{array}{c}\text { The Sense of } \\
\text { Quality of Life } \\
\text { LQS }\end{array}$} & \multicolumn{2}{|c|}{$\begin{array}{c}\text { Social } \\
\text { Characteristics }\end{array}$} & $\mathbf{A}$ & $\mathbf{B}$ \\
\hline $\begin{array}{l}\text { Life Enjoyment } \\
\text { Happiness }\end{array}$ & & 9 & $\begin{array}{l}\text { Educational } \\
\text { Level }\end{array}$ & $\begin{array}{c}\mathbf{0 , 1 0 3} \\
(\mathbf{p}=\mathbf{0 , 0 0 0 )}\end{array}$ & $\begin{array}{c}1,796 \\
(p=0,000)\end{array}$ \\
\hline Life Quality & \multirow{3}{*}{$\begin{array}{c}\text { The Sense of } \\
\text { Quality of Life } \\
\text { LQS }\end{array}$} & \multicolumn{2}{|c|}{$\begin{array}{l}\text { Financial (Economic) } \\
\text { Characteristics }\end{array}$} & $\mathbf{A}$ & $\mathbf{B}$ \\
\hline Life Enjoyment & & 12 & $\begin{array}{l}\text { Economic } \\
\text { Aytonomy }\end{array}$ & $\begin{array}{c}\mathbf{0 , 2 6 4} \\
(p=0,000)\end{array}$ & \multirow{2}{*}{$\begin{array}{c}1,663 \\
(p=0,000)\end{array}$} \\
\hline Happiness & & 13 & Annual income & $\begin{array}{c}\mathbf{0 , 1 7 6} \\
(\mathbf{p}=\mathbf{0 , 0 0 0 )}\end{array}$ & \\
\hline Life Quality & \multirow{3}{*}{$\begin{array}{l}\text { The Sense of } \\
\text { Quality of Life } \\
\text { LQS }\end{array}$} & \multicolumn{2}{|c|}{$\begin{array}{c}\text { Health } \\
\text { Characteristics }\end{array}$} & $\mathbf{A}$ & B \\
\hline Life Enjoyment & & 21 & $\begin{array}{l}\text { Physical } \\
\text { Energy }\end{array}$ & $\begin{array}{c}\mathbf{0 , 3 8 7} \\
(p=0,000)\end{array}$ & \multirow{2}{*}{$\begin{array}{c}1,047 \\
(p=0,000)\end{array}$} \\
\hline Happiness & & 15 & Health Sense & $\begin{array}{c}0,186 \\
(p=0,000)\end{array}$ & \\
\hline
\end{tabular}
Characteristics through Linear Regression

It also appears that LQS (1 to 5 values) is related to Economic Autonomy (1 to 2 Accuracy) and Annual Income (integer values 1 to 5 ) as variables of Financial Characteristics, with the following relationship:

$$
\text { LQS = 0,264 (Economic Autonomy })+0,176(\text { Annual Income })+1,663
$$

Finally, it appears that LQS (values 1 to 5) are related to Physical Energy (1 to 5) and Health Sense (1 to 5) as Health Characteristics variables with the following relationship:

\section{LQS = 0,387 (Physical Energy) + 0,186 (Health Sensitivity $)+1,047$}

Of the above, it is obviously more pronounced the proportional relationship of Life Quality Satisfaction with the Health Characteristics of Respondents, the less pronounced or proportional relationship of Life Quality Sense with the Economic Characteristics of Respondents and even less pronounced or proportional relationship of Life Quality Sense with Age and the Educational Level, as Demographic and Social Characteristics of Respondents respectively.

These results are in line with the previously mentioned studies for the cumulative effects of long-term economic distress seems on the health of older people (McDonough \& Berglund, 2003; Benzeval \& Judge, 2001; Lynch et al., 1997) as well as the relation of education to the growing disparity in the health status of the elderly (Dupre, 2008; Mirowsky \& Ross, 2008; Willson et al., 2007; Mirowsky \& Ross, 2005).

The depiction of the economic and social characteristics as well as the state of health of the elderly among the 
different Centers for Open Elderly Protection of Greece is achieved through the use of the ArcMap software, in which all the table data is imported.

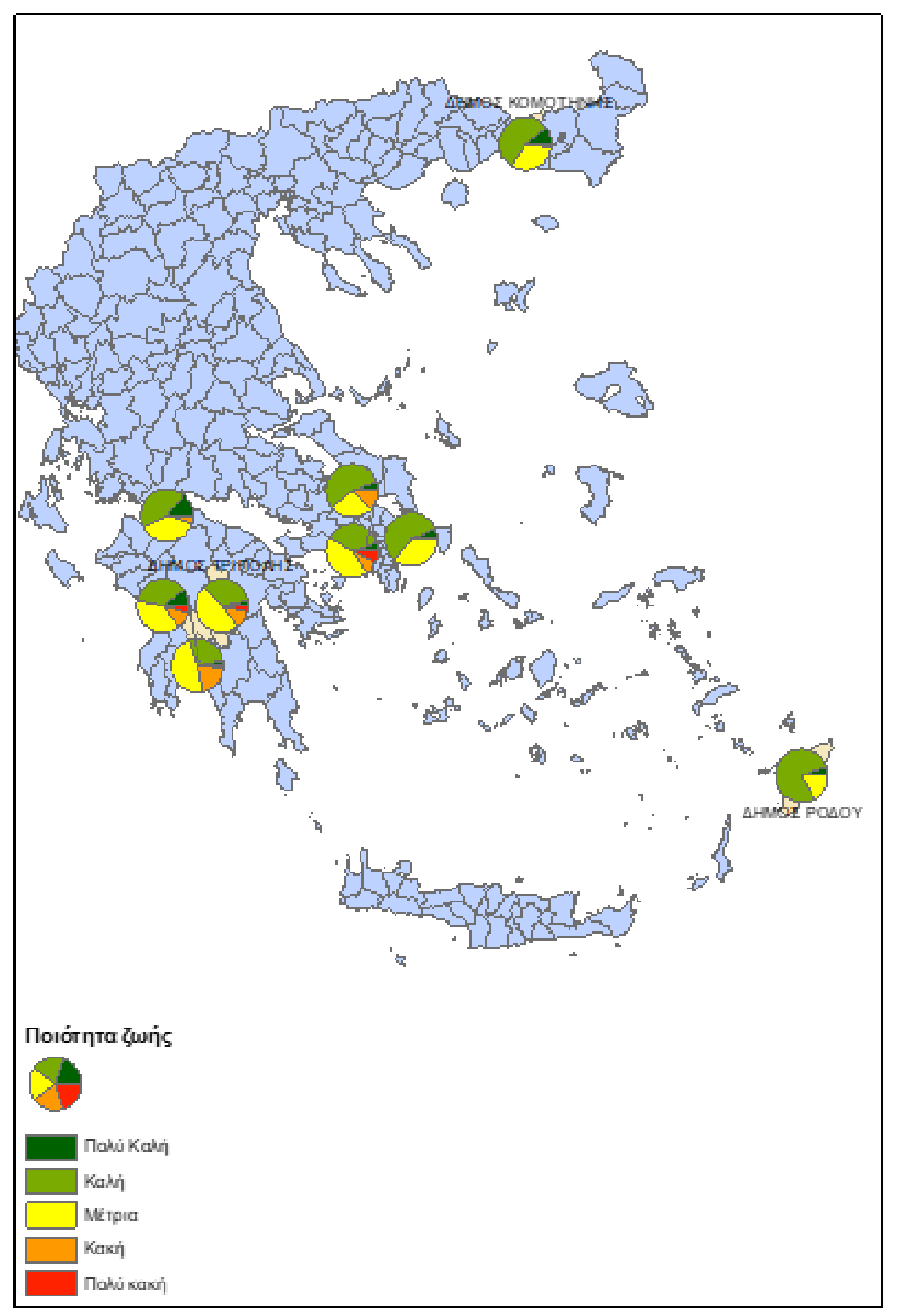

Chart 1. The use of GIS. Authors' survey

The figures are plotted in the corresponding geographical locations on the maps, giving the person concerned a full picture of the geographical distribution of economic and social characteristics and, in particular, of the health status of the elderly by region (see Chart 1 ). Thus, the public institutions and health service providers concerned are given the opportunity to take prompt decisions on their actions.

\section{Conclusions}

The aim of the survey was to investigate the socio-economic indicators that affect the health level of the elderly. The main objectives of the survey were to record the current elderly profile, explore the perception of the elderly about the impact of the economic crisis on their health status and lifestyle, assess the factors that shape the quality of life of the elderly, the degree of correlation of the socio-economic indicators with the quality of life of the elderly in research and the investigation of the differentiation of the degree of correlation of the 
socio-economic indicators with the quality of life of the elderly.

From the previous presentation of results it is clear that there is an obvious proportional relation of the Sense of Quality of Life with the Health Characteristics of the respondents, a less pronounced proportional relationship of the Sense of Quality of Life with the Financial (Economic) Characteristics of the respondents and even less pronounced proportional relationship of the Sense of Quality of Life with Age and the Educational Level, as Demographic and Social Characteristics of respondents respectively.

Given the usefulness of GIS and their application in the fields of physical health, mental health, health services and general health management, the results of the survey were plotted in the corresponding geographical locations on the maps, providing the person concerned with a complete picture of the geographical distribution of the socio-economic indicators that affect the level of health of the elderly per region.

The limitations of research were more bureaucratic, related to the issue of each license. Another limitation was the difficulty of completing the online questionnaire as it is addressed to elderly people who are less familiar with new technologies and computers. A third problem was the relative difficulty of understanding some of the questionnaire questions from some elderly people, mainly because of their age. Also, the credibility of the survey depends on the sincerity of respondents.

Given the usefulness of such health surveys, presented graphically in charts, it is proposed to enable public officers to have direct access to these data for finding immediate solutions for each region of the state, whenever needed. It is also useful to expand these types of surveys in other countries, notably the European Union, with a view to the wider collection and evaluation of data and the comparative presentation of data and surveys in the Member States of the Union. Moreover it is useful to expand such surveys to various other ages and social groups, such as adolescents, young people, migrant groups, minorities, disabled etc.

\section{References}

Adler, N., \& Ostrove, J. (1999). "Socioeconomic Status and Health: What We Know and What We Don't". Annals of the New York Academy of Sciences, 896, 3-15. https://doi.org/10.1111/j.1749-6632.1999.tb08101.x

Andrulis, D. P. (1998). "Access to Care Is the Centerpiece in the Elimination of Socioeconomic Disparities in Health". Annals of Internal Medicine, 129, 412-416. https://doi.org/10.7326/0003-4819-129-5-199809010-00012

Antonovsky, A. (1967). "Social class, life expectancy, and overall mortality". Milbank Memorial Fund Q, 45, 31-73, CrossRef Web of Science. https://doi.org/10.2307/3348839

Beckett, M. (2000). "Health Inequalities in Later Life: An Artifact of Mortality Selection?". Journal of Health and Social Behavior, 41, 106-119. https://doi.org/10.2307/2676363

Benzeval, M., \& Judge, K. (2001). "Income and Health: The Time Dimension.” Social Science and Medicine, 52, 1371-1390. https://doi.org/10.1016/S0277-9536(00)00244-6

Börsch-Supan, A., \& Jürges, H. (2005). The Survey of Health, Aging, and Retirement in Europe. Methodology. Mannheim, Mannheim Research Institute for the Economics of Aging (MEA).

Börsch-Supan, A., Brugiavini, A., Jürges, H., Kapteyn, A., Mackenbach, J., Siegrist, J., \& Guglielmo, W. (2008). First Results from the Survey of Health, Ageing and Retirement in Europe (2004-2007). Starting the Longitudinal Dimension. Mannheim Research Institute for the Economics of Aging (MEA), http://www.share-project.org/t3/share/uploads/tx_sharepublications/BuchSHAREganz250808.pdf

Caraher, M., Dixon, P., Lang, T., \& Carr-Hill, R. (1998). “Access to Healthy Foods: Part I. Barriers to Accessing Healthy Foods: Differentials by Gender, Social Class, Income and Mode of Transport". Health Education Journal, 57, 191-201. https://doi.org/10.1177/001789699805700302

Carone, G., \& Costello, D. (2006). “Can Europe afford to grow old?". Finance and Development, 43(3), 1-9.

Cohen, D. A., Thomas, A. F., \& Karen, M. (2003). "Why Is Poverty Unhealthy? Social and Physical Mediators". Source Social Science \& Medicine, 57, 1631-1641. https://doi.org/10.1016/S0277-9536(03)00015-7

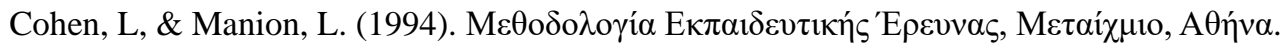

Darmon, N., Ferguson, E. L., \& Briend, A. (2002). "A Cost Constraint Alone Has Adverse Effects on Food Selection and Nutrient Density: An Analysis of Human Diets by Linear Programming". The Journal of Nutrition, 132, 3764-3771. https://doi.org/10.1093/jn/132.12.3764 
Dupre, M. E. (2008). "Educational Differences in Health Risks and Illness over the Life Course: A Test of Cumulative Disadvantage Theory". Social Science Research, 37, 1253-1266. https://doi.org/10.1016/j.ssresearch.2008.05.007

Evans, G. W., \& Katrowitz, E. (2002). "Socioeconomic Status and Health: the Potential Role of Environmental Risk Exposure". Annual Review of Public Health, 23, 303-331. https://doi.org/10.1146/annurev.publhealth.23.112001.112349

Ezatti, M., Utzinger J., Cairncross, S., Cohen, A. J., \& Singer B. H. (2005). "Environmental risks in the developing world: exposure indicators for evaluating interventions, programmes and policies". Journal of Epidemiology and Community Health, 59, 15-22. https://doi.org/10.1136/jech.2003.019471

Feinstein, J. S. (1993). “The Relationship Between Socioeconomic Status and Health.” Milbank Quarterly, 71, 279-322. https://doi.org/10.2307/3350401

Feldman, J. J., Makuc, D, \& Kleinman, J. C., et al. (1989). "National trends in educational differentials in mortality". Am J Epidemiol, 129, 919-933. https://doi.org/10.1093/oxfordjournals.aje.a115225

Foley, R. (2002). "Assessing the applicability of GIS in a health and social care setting: planning services for informal carers in East Sussex, England". Social Science \& Medicine, 55, 79-96. https://doi.org/10.1016/S0277-9536(01)00208-8

Fradelos, E., Papathanasiou, I., Mitsi, D., Tsaras, K., Kleisiaris, Ch., \& Kourkouta, L. (2014). "Health Based Geographic Information Systems (GIS) and their Applications". Acta Inform Med., Dec 22(6), 402-405. https://doi.org/10.5455/aim.2014.22.402-405

Garner, B., Zhou, Q., \& Parolin, B. (1993). "The Application of GIS in the Health Sector: Problems and Prospects", Proceedings of the 4th European Conference on Geographical Information Systems, 29 March 1 April 1993, Genoa, Italy, pp 1350-1357.

Goldman, D., \& Smith, J. P. (2002). "Can Patient Self-Management Help Explain the SES Health Gradient?". Proceedings of the National Academy of Sciences of the United States of America, 99, 109-129. https://doi.org/10.1073/pnas.162086599

Grundy, E, \& Holt, G. (2001). "The socioeconomic status of older adults: How should we measure it in studies of health inequalities?". J Epidemiol Community Health, 55, 895-904. https://doi.org/10.1136/jech.55.12.895

Haan, M., Kaplan, G. A., \& Camacho, T. (1987). "Poverty and health: prospective evidence from the Alameda County Study". Am J Epidemiol, 125, 989-998. https://doi.org/10.1093/oxfordjournals.aje.a114637

Hanchette, C. L. (2003). “Geographic Information Systems”, in O'Carroll, P.W., Yasnoff, Y.A., Ward, M.E., Ripp, L.H., Martin, E.L. (Ed.), Public Health Informatics (pp. 431-466). New York, NY: Springer. https://doi.org/10.1007/0-387-22745-8_21

Hayflick, L. (1998). "How and Why We Age", Experimental Gerontology, 33, 639-653. https://doi.org/10.1016/S0531-5565(98)00023-0

Hayward, R. A., Shapiro, M. F., Freeman, H. E., \& Corey, C. R. (1988). "Who Gets Screened for Cervical and Breast Cancer? Results from a New National Survey". Archives of Internal Medicine, 148, 1177-1181. https://doi.org/10.1001/archinte.1988.00380050181026

Herd, P., Goesling, B., \& House, J. S. (2007). "Socioeconomic Position and Health: The Differential Effects of Education versus Income on the Onset versus Progression of Health Problems". Journal of Health and Social Behavior, 48, 223-238. https://doi.org/10.1177/002214650704800302

House, J. S. (2002). "Understanding Social Factors and Inequalities in Health: 20th Century Progress and 21st Century Prospects". Journal of Health and Social Behavior, 43, 125-142. https://doi.org/10.2307/3090192

House, J. S., Kessler, R. C., Herzog, A. R., Mero, R. P., Kinney, A. M., \& Breslow, M. J. (1990). "Age, Socioeconomic Status, and Health." The Milbank Quarterly, 68, 383-411. https://doi.org/10.2307/3350111

House, J. S., Lantz, P. M., \& Herd, P. (2005). "Continuity and Change in the Social Stratification of Aging and Health over the Life Course: Evidence from a Nationally Representative Longitudinal Study from 1986 to 2001/2002 (Americans' Changing Lives Study)", Journals of Gerontology Series B Psychological Sciences and Social Sciences, 60, 15-26. https://doi.org/10.1093/geronb/60.Special_Issue_2.S15

House, J. S., Lepkowski, J. M., Kinney, A. M., Mero, R. P., Kessler, R. C., \& Herzog, A. R. (1994). "The Social 
Stratification of Aging and Health". Journal of Health and Social Behavior, 35, 213-234. https://doi.org/10.2307/2137277

Huisman, M., Kunst, A. E, \& Andersen, O., et al. (2004). "Socioeconomic inequalities in mortality among elderly people in 11 European populations". J Epidemiol Community Health, 58, 468-475. https://doi.org/10.1136/jech.2003.010496

Kapteyn, A. (2008). "Comparison Between SHARE, ELSA, and HRS”, in: Börsch-Supan, A., Brugiavini, A., Jürges, H., Kapteyn, A., Mackenbach, J., Siegrist, J., Guglielmo, W. (2008). First Results from the Survey of Health, Ageing and Retirement in Europe (2004-2007). Starting the Longitudinal Dimension.

Kitagawa, E. M., \& Hauser, P. M. (1973). Differential mortality in the United States: a study in socioeconomic epidemiology, Cambridge, MA: Harvard University Press. https://doi.org/10.4159/harvard.9780674188471

Lantz, P. M., House, J. S., Lepkowski, J. M., Williams, D. R., Mero, R. P., \& Chen, J. (1998). "Socioeconomic factors, health behaviors and mortality". Journal of the American Medical Association (JAMA), 279, 1703-1708. https://doi.org/10.1001/jama.279.21.1703

Lantz, P. M., House, J. S., Mero, R. P., \& Williams, D. R. (2005). "Stress, life events, and socioeconomic disparities in health: results from the Americans' Changing Lives Study". J. Health Soc. Behav., 46, 274-288. https://doi.org/10.1177/002214650504600305

Lin, N., \& Ensel. W. M. (1989). "Life Stress and Health: Stressors and Resources." American Sociological Review, 54, 382-399. https://doi.org/10.2307/2095612

Lowry, D., \& Xie Y. (2009). "Socioeconomic Status and Health Differentials in China: Convergence Or Divergence at Older Ages?”. Population Studies Center Research Report 09-690. October 2009.

Lynch, J. W., Kaplan, G. A., \& Shema, S. J. (1997). "Cumulative Impact of Sustained Economic Hardship on Physical, Cognitive, Psychological, and Social Functioning”. New England Journal of Medicine, 337, 1889-1895. https://doi.org/10.1056/NEJM199712253372606

Machenbach, J. P., Kunst, A. E., \& Cavelaars, A. E., et al. (1997). "Socioeconomic inequalities in morbidity and mortality in western Europe". The EU Working Group on Socioeconomic Inequalities in Health. Lancet, 349, 1655-1659. https://doi.org/10.1016/S0140-6736(96)07226-1

Marmot, M., Ryff, C. D., Bumpass, L. L., Shipley, M., \& Marks, N. F. (1997). "Social Inequalities in Health: Next Questions and Converging Evidence". Social Science and Medicine, 44, 901-910. https://doi.org/10.1016/S0277-9536(96)00194-3

McDonough, P., \& Berglund, P. (2003). "Histories of Poverty and Self-Rated Health Trajectories." Journal of Health and Social Behavior, 44, 198-214. https://doi.org/10.2307/1519808

Menchik, P. L. (1993). "Economic status as a determinant of mortality among black and white older men: does poverty kill?”. Pop Stud, 47, 427-436, CrossRef. https://doi.org/10.1080/0032472031000147226

Mirowsky, J., \& Ross, C. E. (1998). "Education, Personal Control, Lifestyle and Health: A Human Capital Hypothesis". Research on Aging, 20, 415-449. https://doi.org/10.1177/0164027598204003

Mirowsky, J., \& Ross, C. E. (1999). "Economic Hardship across the Life Course". American Sociological Review, 64, 548-569. https://doi.org/10.2307/2657255

Mirowsky, J., \& Ross, C. E. (2005). "Education, Cumulative Advantage and Health.” Aging International, 30(1), 27-62. https://doi.org/10.1007/BF02681006

Mirowsky, J., \& Ross, C. E. (2008). "Education and Self-Rated Health: Cumulative Advantage and Its Rising Importance". Research on Aging, 30, 93-122. https://doi.org/10.1177/0164027507309649

Mirowsky, J., Link, B. G., \& Phelan, J. (1995). "Social Conditions as Fundamental Causes of Disease". Journal of Health and Social Behavior, 35, 80-94. https://doi.org/10.2307/2626958

Najafabadi, A. T. (2009). “Applications of GIS in Health Sciences”. Shiraz E-Medical Journal, 10(4), 221-230.

Palmore, E.B. (1982). "Predictors of the longevity difference: a 25-year follow-up". Gerontologist, 22, 513-518. https://doi.org/10.1093/geront/22.6.513

Rosenbaum, E. (2008). "Racial/Ethnic Differences in Asthma Prevalence: The Role of Housing and Neighborhood Environment". Journal of Health and Social Behavior, 49, 131-145. https://doi.org/10.1177/002214650804900202 
Ross, C. E., \&Chia-Ling, W. (1995). "The Link Between Education and Health". American Sociological Review, 60, 719-745. https://doi.org/10.2307/2096319

Smith, M. J., Goodchild, M. F., \& Longley, P. A. (2007). "Geospatial Analysis - The comprehensive guide to principles, techniques and software tools". Webversion (Oct. 2007). http://www.spatialanalysisonline.com

Taylor, J., Biddulph, P., Davies, M., \& Lai, K. (2013). "Predicting the microbial exposure risks in urban floods using GIS, building simulation and microbial models". Environment International, 51, 182-195. https://doi.org/10.1016/j.envint.2012.10.006

Taylor, S. E., \& Seeman, T. E. (1999). "Psychosocial Resources and the SES-Health Relationship". Annals of the New York Academy of Sciences, 896, 210-225. https://doi.org/10.1111/j.1749-6632.1999.tb08117.x

von dem Knesebeck, O., Verde, P. E., \& Dragano, N. (2006). "Education and Health in 22 European Countries". Social Science \& Medicine, 63, 1344-1351. https://doi.org/10.1016/j.socscimed.2006.03.043

Willson, A. E., Shuey, K. M., \& Elder, G. H. (2007). "Cumulative Advantage Processes as Mechanisms of Inequality in Life Course Health". American Journal of Sociology, 112, 1886-1924. https://doi.org/10.1086/512712

Yasnoff, W. A., \& Miller, P. L. (2003). "Decision Support and Expert Systems in Public Health", in O'Carroll, P.W., Yasnoff, Y.A., Ward, M.E., Ripp, L.H., Martin, E.L. (Ed.), Public Health Informatics (pp. 494-512). New York, NY: Springer. https://doi.org/10.1007/0-387-22745-8_23

Zimmer, Z., \& House, J. S. (2003). "Education, Income, and Functional Limitation Transitions among American Adults: Contrasting Onset and Progression". International Journal of Epidemiology, 32, 1089-1097. https://doi.org/10.1093/ije/dyg254

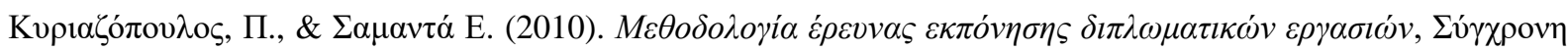

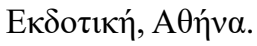

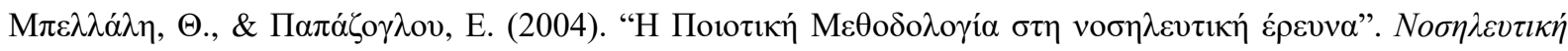
43, 261-270.

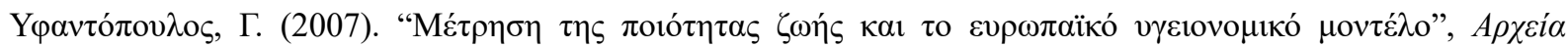

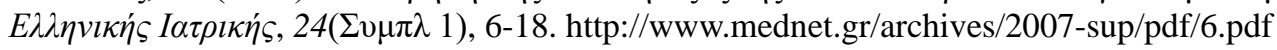

\section{Copyrights}

Copyright for this article is retained by the author(s), with first publication rights granted to the journal.

This is an open-access article distributed under the terms and conditions of the Creative Commons Attribution license (http://creativecommons.org/licenses/by/4.0/). 